\title{
STUDYING TO BECOME A SOCIAL WORKER: EXAMINING THE MOTIVATIONS OF, AND CHALLENGES FACING, STUDENTS AT AN OPEN DISTANCE-LEARNING UNIVERSITY
}

\author{
Nicky Alpaslan, Berto Lombard
}

\section{INTRODUCTION AND PROBLEM FORMULATION}

Unisa represents the only dedicated distance-education institution in South Africa offering open and distance learning to a diverse and changing student population. The student profile reveals a large number mature students and a dramatically increasing number of full-time school leaving students enrolling at this institution. This is because the academic offerings at Unisa are considerably more affordable than those at its counterparts both in the public and private higher education sectors (Unisa 2015 Strategic Plan, 2006:8-10).

A part of Unisa's mission statement claims that it provides "quality general academic and career-focused learning opportunities underpinned by principles of lifelong learning, flexibility, and student-centeredness" (Unisa 2015 Strategic Plan, 2006:8-10). In its pursuit to be studentcentred, and to get to know the bulk of its "consumers of service" (i.e. undergraduate students studying to become social workers), the Department of Social Work at Unisa resolved to put these students and their personal and learning-related contexts on the Department's research agenda. Resulting from this decision, Lawlor (2008) undertook a research project focusing on the topic: "Finding a fit between personal context, learning context and work-related context of students to further practice excellence in social work", with a sample of fourth-year students as one of the interest groups participating in this study. Lintvelt (2008) also focused on the fourthlevel students in the Department when she undertook a study on "The personal context of undergraduate students in social work at Unisa". In a journal article Schenck (2009) discusses the socioeconomic realities of social work students at the University of South Africa, making reference to the findings of Lawlor (2008), Lintvelt (2008) and Wade, a doctoral candidate who was at the time investigating the traumatic experiences of social work students at Unisa in an attempt to highlight the importance of taking socioeconomic factors into consideration when the University plans its student-support programmes. Subsequently Wade (2010) successfully completed her doctoral study focusing on the topic of "Unisa social work students' experiences of trauma: an exploratory study from a person-centred approach".

In view of the fact that all the studies thus far undertaken focused only on the fourth-year/level students in the Department of Social Work, and in continuing with this topic on the Department's research agenda, the researchers decided to investigate the topic of coming to understand student motivations for studying social work, for studying social work specifically at Unisa (as ODL ${ }^{1}$ university), and the challenges they experienced while studying to become

\footnotetext{
${ }^{1}$ Keegan (1996:34) defines "distance education" as "a generic term that includes the range of learning/teaching strategies used by correspondence colleges, open universities, distance departments of conventional colleges... it is a term for education of those who choose not to attend the schools, colleges and universities of the world but study at their home, or sometimes their workplace". According Unisa's Self-evaluation Portfolio for the HEQC Institutional Audit (2008:15), open distance learning "is a multi-dimensional system aimed at bridging the time, geographical and transactional distance between the student and institution, student and lecturers/tutors, students and courseware, and student and peers".
} 
social workers, not focusing only on the fourth-year/level students, but including students from first-year/level up to fourth level in the sample.

After scrutinising the literature focusing specifically on the variables "study to become social workers" specifically "in the context of open distance learning", the researchers found the following state of affairs internationally. In Britain there seems to be a lack of research available on social work and open distance learning (Collins, 2008:426). In the United States of America, while a few studies have produced negative findings (Thyer et al. in Collins, 2008:426), the majority of studies conducted reported positive outcomes for distance-learning programmes (i.e. the educational achievements of distance-education social work students are comparable to those of traditional students (Potts \& O'Hagan in Collins, 2008:426); distancelearning social work students achieve equivalent grades compared to on-campus cohorts (Haga \& Heitkamp in Collins, 2008:426); distance-learning social work students indicate satisfaction levels at least equivalent to those obtained by traditional classroom teaching (Potts \& O'Hagan in Collins, 2008:426). Furthermore, the study by McFall and Freddolino (in Collins, 2008:426) discovered that it was "possible to implement a quality field instruction component in a distance [social work] education setting at least comparable to what was provided on campus and, in some cases, even better". On the local front, and with specific reference to the variables mentioned above, only the studies done by Lawlor (2008), Lintvelt (2008), Schenck (2009) and Wade (2010) were found. In these studies the personal and socioeconomic challenges relating to studying social work were articulated, but as stated above these studies focused only on fourth-level/year social work students.

Through this research endeavour and including social work students from levels one to four, the researchers envisaged revisiting and increasing the knowledge base on the motivations for studying social work and the challenges experienced whilst studying social work at an ODL institution. This research should supply valuable insights to Unisa and its Department of Social Work in revisiting their level of, and commitment to, student-centeredness in providing support to students on their journeying towards becoming social workers in the context of open and distance learning.

\section{RESEARCH QUESTION AND GOAL}

Research questions, not hypotheses, are normally written into the text of qualitative studies (Creswell, 1994:70) and become the signposts to identify the interest and the initial focus of the study (Fossey, Harvey, McDermott \& Davidson, 2002:723; Jansen, in Maree, 2007:68).

The questions formulated at the outset to focus this research project were the following: (1) What are the reasons for students enrolling at an ODL institution for studying to become social workers? (2) What are the motivations of these students for studying to become social workers? (3) What challenges do students experience at an ODL institution while studying to become social workers?

\section{RESEARCH APPROACH AND METHODOLOGY}

In order to answer these research questions, a qualitative research approach was followed. Creswell (2003:40) postulates that a qualitative research approach is opted for when the topic under investigation needs to be explored and "qualitative methods are well suited to the discovery of ... unnamed processes relevant to the lived experience of research participants; [they] provide thick descriptions of phenomena in very specific contexts, [and] elicit and add power to minority "voices"” (Ungar, 2003:85). 
The qualitative paradigm therefore appeared to be the appropriate choice, because it assisted the researchers in their quest to obtain subjective, personal data about the topic under investigation. This approach gave the undergraduate students, as "self-knowing subjects", the opportunity to speak authoritatively about the situation being researched.

Within the qualitative approach, the researchers employed an explorative, descriptive and contextual research design or strategy of inquiry. Given the paucity of information on this topic per se within the context of Unisa as an ODL institution, the researchers employed an explorative research design. Royse (2008:29) notes that the explorative research design is normally employed when one wants to explore a topic on which little information is available (Neuman, 2000:21). Complementary to the explorative research design, a descriptive research design was utilised to allow for a detailed description of what was being explored (Neuman, 2000:21). A contextual design was also used, since the researchers wanted to investigate the phenomenon under study within, and from, a specific context.

Purposive sampling (as a non-probability sampling technique) was employed as the researchers sought participants who were information-rich as a result of their knowledge and ability to describe the phenomenon under study (Donalek \& Soldwisch, 2004:356). Coupled with the purposive sampling technique, the researchers also utilised the convenience sampling technique to select participants who were easily accessible for inclusion in the study.

In selecting participants for inclusion in the sample, the fieldworkers (who were mainly responsible for procuring a sample, collecting and analysing the data) proceeded as described below.

The one fieldworker who was from Gauteng used a gatekeeper (the Florida Unisa Campus workshop facilitator for social work students) to bring her into contact with participants. This workshop facilitator brought the research project to the prospective participants' attention and forwarded the fieldworker's details to them. Interested participants then contacted this fieldworker and in this way she secured five participants (fitting the criteria for inclusion stated below) to interview. The four fieldworkers from KwaZulu-Natal went to the Stalwart Simulane and the Unisa Learning Centre Campuses of Unisa in Central Durban looking for individuals whom they knew were studying social work. Upon encountering these students in the cafeteria, lecture halls and the library, they casually informed them about the research project. Those who showed an interest and willingness to participate were subsequently informed in detail about the research. Furthermore, where the fieldworkers became aware of social work students in the area, they made an effort to obtain such students' contact details from fellow students and the workshop facilitators at these campuses in Durban. They then contacted the students to enquire about their willingness to participate in this study. Through this approach the four fieldworkers in KZN obtained a sample of 15 participants for inclusion in the study. Only participants who met the following criteria were included in the study:

- they were registered as undergraduate students at Unisa at the time;

- they were at locations which were convenient for the interviews;

- they were available and willing to participate in the study, in that they were fully aware of what the study entailed, and participated of their own free will.

With reference to the sample size in qualitative research, various authors point to the fact that qualitative research involves smaller samples than quantitative research does (Fossey et al. 2002:726; Langford, 2001:152; Maree \& Pietersen in Maree, 2007:177). As is usual in qualitative research, no sample size was determined at the outset of the study, but the principle 
of "saturation of data" determined the sample size. The fieldworkers continued with the collection of data from multiple participants until the themes emerging from the data became fully developed and repetitive (Donalek \& Soldwisch, 2004:356; Fossey et al., 2002:72). After conducting 21 semi-structured interviews, transcribing the audio-recordings and reading through the transcriptions, the fieldworkers and the researchers concluded that the data had reached a point of saturation and the process of data collection could therefore be concluded.

Interviewing, using focus groups and participant observation are common modes of qualitative data collection (Fossey et al., 2002:72). Semi-structured interviews were employed by the fieldworkers for collecting the data needed. The contents of the interviews were directed by an interview guide comprising of questions specifically formulated for the purpose of obtaining biographical data about the participants and a limited number of questions pertaining to the topic under investigation. Holloway and Wheeler (1998:55) and Kvale (1996:174) explain that in semi-structured or focused interviews the questions asked are those included in the interview guide (i.e. not in a schedule, as is the case in quantitative research), the focus being on the themes or issues to be covered. The following questions were formulated to address the topic under investigation:

- What are your reasons for studying social work at Unisa as an ODL institution?

- What motivated you to study towards becoming a social worker?

- What are the challenges that you experience whilst studying towards becoming a social worker?

With the consent of the participants, all the interviews were audio-taped. On completion of the data-collection process, the fieldworkers transcribed the audio recordings word for word. Consequently, the process of data analysis commenced as a joint venture between the fieldworkers and the researchers. Creswell (1994:153) contends that the researcher is engaged in several activities during qualitative data analysis. These include collecting the data, transcribing the interviews, sorting the data into categories, formatting the data into a coherent story or picture, and writing the qualitative text. The fieldworkers and the researchers employed the eight steps provided by Tesch (in Creswell, 1994:155; 2003:186) to analyse the data systematically, by segmenting the information into words or categories that subsequently formed the basis of the emerging story or picture.

For the purpose of data verification the researchers employed Guba's model of trustworthiness (as discussed in Krefting, 1991:215-222) which identifies four criteria and strategies for ensuring and establishing trustworthiness, which were therefore used to assess the qualitative research process undertaken.

- The first criterion addressed in establishing trustworthiness is that of truth value, that is, determining to what extent the findings are a true reflection of the "life-worlds" of the participants, as experienced and described by them. The strategy for establishing truth value is credibility. The particular actions taken to achieve credibility included triangulation (i.e. triangulation of data sources [i.e. interviewing multiple participants], and the triangulation of different investigators [i.e. the fieldworkers and the researchers] involved in this research project), peer examination (i.e. regular discussions and consultations between the fieldworkers and the researchers), the interviewing techniques used by the fieldworkers, and the researchers overseeing the fieldwork process.

- The second criterion is applicability or the degree to which findings can be applied to other contexts or settings and groups (i.e. generalisability). Transferability was the strategy 
adopted to achieve applicability. With reference to the transferability of the research findings, Rodwell (in Ungar, 2003:95) writes: "If the findings transfer, it is the responsibility of the reader of the inquiry report to make that determination, since it is only the reader, not the inquirer, who can be familiar with the time and context in which transfer of the findings might be possible." Lincoln and Guba (in Ungar, 2003:95) advise that the researcher has the responsibility to provide a "thick description"" so as to enable someone interested to conclude whether transfer can be contemplated as a possibility. For this reason "dense" descriptions of the research methodology and findings were provided.

- The third criterion in Guba's model (in Krefting, 1991:215-222) is consistency, which is concerned with the extent to which the replication of the study in a similar context or with similar informants will produce the same results. Dependability was the strategy used to ensure consistency. The actions that were taken to ensure that this study was reliable included peer examination of the research methodology, triangulation of data sources and investigators, a dense description of the research methodology and research findings, independent coding (i.e. the fieldworkers analysed their transcriptions independently and the researchers also independently analysed the whole data set), and the implementation of a code-recode procedure (Krefting, 1991:216-217)).

- Neutrality is the fourth and final criterion, and refers to the extent to which the study's findings are free from bias. Lincoln and Guba in Krefting (1991:217) propose that neutrality in qualitative research should consider the neutrality of the data rather than of the researcher, and thus suggested confirmability as the strategy for achieving neutrality. In this study triangulation (as explained above) was employed to achieve confirmability (Krefting, 1991:221-222).

\section{DISCUSSION OF THE FINDINGS}

The research findings presented in the next part of this paper resulted from the analysis of the 21 semi-structured interviews by the five field workers, who analysed the transcribed interviews independently from the researchers. The researchers as a team also analysed the transcribed interviews.

The discussion on the research findings is presented in two sections:

- The biographical profile of the participants;

- A discussion on the themes (and sub-themes) that emerged from the processes of data analysis. This discussion is supported by narratives from the transcribed interviews and complemented by a literature control.

The biographical profile of the participants

The table below provides the biographical particulars of the participants. 
TABLE 1

BIOGRAPHICAL PROFILE OF THE SAMPLE GROUP

\begin{tabular}{|c|c|c|c|c|c|c|}
\hline $\begin{array}{l}\text { Participant/Province } \\
\text { of residence }\end{array}$ & Gender & Age & $\begin{array}{c}\text { Year } \\
\text { of } \\
\text { study }\end{array}$ & Married & $\begin{array}{l}\text { Ethnic } \\
\text { group }\end{array}$ & Dependants \\
\hline 1 (Gauteng) & $\mathrm{F}$ & 48 & 2nd & Yes & White & 2 children \\
\hline 2 (Gauteng) & $\mathrm{F}$ & 21 & $3^{\text {rd }}$ & No & White & None \\
\hline 3 (Gauteng) & $\mathrm{F}$ & Unknown & $3^{\text {rd }}$ & No & White & None \\
\hline 4 (Gauteng) & $\mathrm{F}$ & 37 & $4^{\text {th }}$ & Lives with partner & White & None \\
\hline 5 (Gauteng) & $\mathrm{M}$ & 43 & $4^{\text {th }}$ & Yes & Black & 1 child \\
\hline 6 (Gauteng) & $\mathrm{F}$ & 41 & 4th & Yes & Black & 2 children \\
\hline $7(\mathrm{KZN})$ & $\mathrm{F}$ & 36 & 2nd & Yes & Indian & 2 children \\
\hline $8(\mathrm{KZN})$ & $\mathrm{F}$ & 21 & $3 \mathrm{rd}$ & No & Black & None \\
\hline $9(\mathrm{KZN})$ & $\mathrm{F}$ & 23 & $3 \mathrm{rd}$ & No & Black & None \\
\hline $10(\mathrm{KZN})$ & $\mathrm{F}$ & 23 & 4th & No & Indian & None \\
\hline $11(\mathrm{KZN})$ & $\mathrm{F}$ & 34 & $3 \mathrm{rd}$ & No & Indian & None \\
\hline $12(\mathrm{KZN})$ & $\mathrm{F}$ & 19 & $1 \mathrm{st}$ & No & Black & None \\
\hline $13(\mathrm{KZN})$ & $\mathrm{F}$ & 26 & 1 st & No & Black & 2 children \\
\hline $14(\mathrm{KZN})$ & $\mathrm{F}$ & 50 & 4th & Yes & Indian & None \\
\hline $15(\mathrm{KZN})$ & $\mathrm{F}$ & 22 & $3 \mathrm{rd}$ & Yes & Black & 2 children \\
\hline $16(\mathrm{KZN})$ & $\mathrm{F}$ & 20 & 1 st & No & Black & None \\
\hline $17(\mathrm{KZN})$ & $\mathrm{F}$ & 27 & $1 \mathrm{st}$ & No & Black & None \\
\hline $18(\mathrm{KZN})$ & $\mathrm{F}$ & 20 & 2nd & No & Indian & None \\
\hline $19(\mathrm{KZN})$ & $\mathrm{F}$ & 40 & $3 \mathrm{rd}$ & Yes & Black & 4 children \\
\hline $20(\mathrm{KZN})$ & $\mathrm{F}$ & 29 & 4 th & No & Indian & None \\
\hline $5021(\mathrm{KZN})$ & F & 23 & 4 th & No & Black & None \\
\hline
\end{tabular}

Looking at the table above it becomes clear that the majority of the participants in this study were from KwaZulu-Natal (KZN). The reason for this was that one of the fieldworker resided in Gauteng, while the rest of the fieldworkers who particiapted in this research project were from KZN and used convenience sampling as a means to purposively select participants who were easily accessible for inclusion in the study.

With the exception of one participant, all the participants are female and this corresponds with the trend that social work is a female-orientated profession (Christie \& Kruk, 1998:25).

Discussion of the themes and sub-themes and a literature control

From the process of data analysis three major themes emerged, namely:

- participants' reasons for enrolling at an ODL institution for study to become social workers;

- participants' motivations for starting and continuing their studies to become social workers; 
- challenges encountered by participants while studying to become social workers.

These themes and related sub-themes (where applicable) are discussed in the next section of this paper.

\section{THEME 1: PARTICIPANTS' REASONS FOR ENROLLING AT AN ODL INSTITUTION FOR STUDYING TO BECOME SOCIAL WORKERS}

Under this sub-heading the participants' reasons for enrolling at an ODL institution for studying to become social workers will be presented.

Most of the participants were either full-time or part-time employed and stated this as one of the reasons why they chose to study at Unisa as an ODL institution. The following storylines make reference to this:

Unisa was the only University in Durban that offered long-distance [learning] and that suited my needs. That's the reason why I chose Unisa, because I was keeping a full-time job.

Unisa is internationally recognised ... [for] ... its distance learning which is convenient for me as I am a working-class person. I can keep my job and achieve my study goals at the same time.

The reason provided above for choosing to study at Unisa as an ODL institution corroborates the finding in Lintvelt's (2008:72) research, where 40 out of 90 respondents indicated that they decided to study at Unisa because they were working when they commenced their studies. By being an ODL institution, Unisa is fulfilling a critical social mandate to serve people who would otherwise not have access to education - either for financial reasons, or because they are employed, or living in remote areas, or because they cannot access residential universities owing to disability (Unisa Self-evaluation Portfolio for the HEQC Institutional Audit, 2008:15).

Another reason why the participants decided to study at Unisa as ODL institution was because it was accessible or convenient and financially affordable. The following storylines testify to this:

...Unisa is the most affordable university.

Unisa is also assisting people who would not have access to education. The university provides bursaries ... Many students rely on these to complete their studies.

With reference to the affordability of study at Unisa, Kilfoil (in Schenck, 2009:299) confirms that Unisa's students also include those who have just come straight from school, because it is the most affordable institution. Some even made mention of the financial assistance they obtained through Unisa (confirming the sentiment in the last quotation above.)

\section{THEME 2: PARTICIPANTS' MOTIVATIONS FOR STARTING AND CONTINUING THEIR STUDIES TO BECOME SOCIAL WORKERS}

From the data collected it became clear that various motives led the participants to start and subsequently continue with their studies to become social workers. These motives will be presented as sub-themes below.

Sub-theme: The congruence or fit between the nature of social work and the self-structure of the individual and social work as means through which this self-structure could be expressed as motivation to become social workers 
Some of the participants indicated that the nature of social work (i.e. what social work is all about) is congruent with who they are. Therefore, to enrol for studies in social work and to eventually qualify as a social worker was not merely a career choice, but rather a complementary means through which they could realise themselves and find full expression of their identities (i.e. who they are). The following excerpts from the transcribed interviews testify to this:

Social work is different from any other job because you use yourself ... it's who you are.

I think you are born a social worker.

It's so much who I am and it sort of I don't know - fits with me ... it fits with the way I think.

These theme and storylines resonate with a finding in Holme and Maizels' research (in Christie \& Kruk, 1998:23) pointing to the fact that individuals' motives for becoming social workers include that they are looking for some form of self-realisation through their work.

Sub-theme: Participants' passion for helping others in response to their own challenging experiences and those of others as motive to start studying to become social workers

From the storylines quoted below it became clear that the participants' passion for helping others originated from their own personal circumstances and suffering while growing up; according to Christie and Kruk (1998:25), this can be classified under "personal motives" for studying social work.

As I grew up, my mother raised me as a single parent. So she was, she has facing many challenges, in such a way that I to move from my house to live with relatives, which led me to experiencing many, many difficulties in my life ... I did not get support from my father and my family.

I grew up in an abusive environment. I told myself that I want to become a social worker when I grow up.

To confirm this, Waterman (2002) refers to DiCaccavo's view that people in the helping professions in general (psychologists, counsellors, social workers) tend to report higher levels of emotional neglect, abuse and other adverse experiences. Waterman (2002) adds to this and states: "These people, working in the helping professions, are referred to in the literature as 'wounded healers'. They report great dissatisfaction in their childhoods, and their work in counselling professions is not only an extension of childhood roles, but also an attempt to come to terms with their own hurts and disappointments".

The remarks point to a heart-felt passion and love for, as well as a sincere interest in people, their needs and suffering; the motivations expressed to address and respond to this include the following:

I realised how much I had a heart and passion for the people here.

My passion for making the world a better place and helping people in need.

... With experiences of life and social problems that are around us these days then I saw a need of really becoming a social worker now.

It's the high rate of abuse, you know. Especially in the township, you see this kind of thing. The incidents that we've seen happening in the townships motivated us to choose this course. 
In support of the above sub-themes and supporting storylines, Ife (2001:142) postulates that choosing social work as a career path is not just the consequence of rational decision-making, but it is in some instances rather primarily based on an emotional decision-making process. A passion to help others, to make the world a better place, as well as a commitment to bring about change in human pain and suffering, might be the overriding motives for choosing a career in social work. These motives are confirmed by Waterman (2002), who observes that "altruism" and the desire to help others is a very common trait amongst social service workers, as well as their belief that they can contribute to society and be catalysts for social change.

From the literature consulted, the researchers learnt that a person's passion informs his or her career choice and motivates a person to persevere in obtaining some form of qualification and employment where this passion can be expressed (Boylston \& Blair in Landow, 2006:131; Peers, 2003:171).

Sub-theme: Participants' pursuing of their dreams and goals as motivation to start and continue studying to become social workers

Alderman (2004:106) refers to goals as "cognitive representations of the future", and as such goals become motivators in that they provide standards for self-evaluation processes.

The fact that the participants were pursuing dreams and goals (of studying to become qualified social workers) provided the necessary motivation to start and continue their studies. Looking at the remarks below in confirmation of this sub-theme, the researchers realised that the participants' goals and dreams in studying to become social workers fit under what is classified in Christie and Kruk (1998:25) as:

- "Personal motives" (i.e. responses referring to addressing and improving personal circumstances);

- "Professional/career motives" (i.e. responses that stressed profession/career prestige, economic rewards, career flexibility and the joining of a profession);

- Motives for attending to "clients' needs" and affecting "societal change" and "promoting social change through social work".

I'm going to be able to use it [social work]. I'm going to be in a position to make a change. And that keeps me going.

The reward of finally qualifying and graduating of becoming a qualified social worker.

[I need to qualify, so] I can feed myself and my children. I ... my life, can change from here.

Once you graduate, you will be registered with the Council [referring to the SA Council for Social Service Professions] and be able to use this degree, even overseas, like in London. I've heard that social workers get paid very well there.

The following statements point to the fact that some of the participants' goals and dreams were of an altruistic ${ }^{2}$ nature:

We will be able to help society through working hard.

Hearing from the media that the social workers are short (sic) and I can make a difference.

\footnotetext{
${ }^{2}$ This aspect was also referred to in the discussion of the previous sub-theme.
} 
Some of the participants also indicated the desire to formalise their knowledge and skills to allow them to go further, as a few of them started with volunteer work and subsequently decided to go full-time into the social work profession. This was poignantly articulated by one participant, who said: "It's actually a volunteer choice that's become a career choice". The participants' desire to obtain a professional qualification and to be part of a profession can be deduced from the following statements:

\section{I wanted to become more involved in a professional capacity.}

What keeps me motivated is that eventually I, if I do pass, I will have realised my dream of working as a professional with the community.

As a non-professional person, sometime people find it easy to come and talk to me but you know when you are a professional you know exactly what you are doing.

In support of this sub-theme, Peers (2003:171) notes that adult learners are more aware of their (career) goals and this allows them to become more motivated, persistent and tenacious in realising these goals. Rogers and Howard (2009:255) also confirm the above notion that adult learners return to education to formalise their knowledge and skills. They view adult learners as "formalisers" in the sense that adult learners turn to tertiary and further education to "formalise the knowledge" that they have acquired "informally". This opens up career opportunities and advancement and in this way many volunteers study to formalise their knowledge and enter a professional career.

Aside from the motivation to achieve certain ends, participants also mentioned that they enjoyed what they were studying and this motivated them to continue with their studies.

Sub-theme: The enjoyment of what they were studying and its usability as motivation for participants to continue with their studies to become social workers

The enjoyment of what they were studying was referred to as follows by the participants:

I absolutely love what I'm learning ... I think I'm passionate about what I'm studying.

I feel this like well up of excitement in me because I'm learning new stuff.

The fact that the participants can apply in practice what they have learnt also served as a motivation to continue with their studies (as can be deduced from the following quotations):

What's motivated me as well is that I actually am finding it very useful.

The same reason that keeps me motivated it's my biggest resource. Without a doubt is getting out there and using what I've learnt.

With reference to this sub-theme, a few participants also mentioned that they wanted to know more and would therefore continue studying. This was poignantly reflected by one participant:

I don't know it all, and that keeps me motivated because I know there's a hook at the end somewhere that I just need to get to.

This need "to know more", or the desire to learn, is confirmed by Rogers and Howard (2009:257), who are of the view that some adult learners can be labelled as having a "thirst for knowledge". Mosimege's (2006:96) study on the experiences of mature women students in higher education postulates that students value the ability to speak with knowledge and confidence and know that this can only be acquired through the process of learning new material. Therefore, they are motivated to study and continue with their studies. 
The participants' accounts of their current achievements, or "having come so far", were also identified as a sub-theme in motivating them to continue with their studies towards becoming social workers.

Sub-theme: Current achievements as motivation towards continuing their studies to become social workers

Apart from four participants, the rest have at least completed the first level of their studies towards obtaining a Bachelor's Degree in Social Work at the time of the research. Their achievement can be viewed as a "push factors" in that it was pushing them forward and fuelled the desire to continue with their studies. The "pull factor" was the dream of qualifying as social workers and the desire to finish their studies. The following quotations underscore this:

It's been such a long process and journey to get here that it's not going to be easy for me to not wanting to do it.

The first thing is that ... I did the social work four years in three years if I pass this year. So I was able to survive the first year and the second year which I did in the first yearin one year.

Two participants shared how the fact that they were completing their social work studies was motivational:

[There is] a sense of motivation that, in the sense that I'm going to finish something.

This year is the final year so I have gone a long way so it keeps me to be right here and the other thing I know is this saying when they say "There's a light at the end of the tunnel" - it becomes very dark when there's going to be a light. You know, so it keeps me going to say I can't back out now, I've just travelled a long way.

The effects of achievement on motivation were found to be confirmed in the achievement motivation theory of Rabideau (2005). According to Rabideau (2005), the "achievement motivation theory" states that certain motives and goals drive the individual. The motives that drive are the desire for achievement and the avoidance of failure. Achievement goals are viewed as more solid cognitive representations pointing individuals toward a specific end. Achievement-motivated people prefer to work on a problem rather than to leave the outcome to chance, and they seem to be more concerned with their personal achievement than with the rewards of success (Romando, 2007).

The next section considers the theme focusing on the challenges encountered by the participants while studying to become social workers.

\section{THEME 2: CHALLENGES ENCOUNTERED BY PARTICIPANTS WHILE STUDYING TO BECOME SOCIAL WORKERS}

The participants mentioned various challenges they had to face while studying to become social workers. These challenges were divided into (1) challenges experienced in relation to distance education; (2) time constraints as a challenge; and (3) the challenge of balancing multiple roles.

\section{Sub-theme: Challenges experienced in relation to distance education}

On reviewing the accounts of the participants it became clear that the challenges experienced in relation to distance education can be sub-divided into (1) institutional challenges (i.e. challenges experienced in relation to contact with the service departments at Unisa); (2) departmental challenges (i.e. challenges experienced specifically concerning participants' 
contact with the Department of Social Work at Unisa) and (3) regional challenges (i.e. challenges relating specifically to the Durban Regional Office of the Department of Social Work and Unisa's Durban Campus).

Category 1: Challenges faced in relation to Unisa as an institution with reference to specific service departments

The participants experienced various challenges in their contacts with various service departments at Unisa which are highlighted below.

Some of the participants mentioned that they had difficulty in accessing their examination results because of a delay in the payout of scholarships. The following comments attest to this:

Well, first there are financial issues, where the scholarship hasn't settled the account and it is difficult for me to obtain my results.

Yes, I am happy because it's [referring to the scholarship] providing me with finance but then they are delaying to pay in such a way you cannot get your results, they [are] not paying in time.

Another challenge mentioned was the late delivery of study material and the fact that students could no longer go and collect their study material at the various regional offices. One participant poignantly referred to this as follows: “... there has always been a problem in my experience with Unisa in terms of having your study guides and your tutorial letters delivered to you on time. So if you didn't register early, you were left without your study material for 3 to 4 months into the year". In Lintvelt's study (2008:77), 29 out of 90 respondents also experienced challenges concerning the study material at Unisa and specific reference was made to the fact that "study material was not always available", "delayed", "out of stock", or "wrong material was sent". Coupled with this challenge was another, namely students living in deep rural areas who experienced limited access to postal services and unreliable postal service. This delayed the receipt of study material or even caused the students not to receive any study material.

Registration at Unisa was mentioned as a challenge. In connection with this challenge, the participants informed the fieldworkers that they were incorrectly advised by counsellors to register for modules not needed or required for the qualification; application forms were not processed on time, which delayed the registration process; call-centre staff putting them "on hold for long", were "rude" to them, and "not knowing themselves what was going on". The following remarks made by participants are provided in confirmation of this:

Registrations this year was a problem. They [referring to applications] were not being processed on time and I had to keep phoning the call centre after the "on line" registration in order for the application to get processed. The long queues make it too difficult for registration at the campus and it was very time consuming.

The person who was doing the registration put in the wrong module.

If I have query and I want to be able to speak to somebody to help me. If by any chance I do get through to somebody, most of the people do not even know what I am talking about to do with course selection.

In the first place it's a schlep to get a hold of somebody in Pretoria because of the switchboard ... your call will be diverted from this department to that department. You just have people on the receiving end that are so rude and that are so blunt. 
The challenges referred to by the participants above correspond with a finding in Lintvelt's (2008:75) research study where 19 out of 90 respondents made mention of challenges experienced with the registration section at Unisa.

Category 2: Challenges faced in relation to Unisa's Department of Social Work

Participants indicated a difficulty in understanding the content of the modules and were often unsuccessful in reaching lecturers for help. Difficulty in understanding the content was expressed as follows by participants:

I've battled with the content of the social work modules.

The books are so bloody confusing as well ... you have no idea what they want from you half the time.

Being unsuccessful in attempts to make contact with the lecturers in the Department was articulated as follows:

The lecturers are not readily accessible. You get their numbers, you phone the office, especially social work department. The lecturers are not easy to find over the phone.

Unisa is a distance learning ... I didn't get to meet the lecturers quite often, and sometimes when you phone, you want to ask a particular question, but the lecturer is not available.

This challenge is also mentioned by Galusha (nd.), who states that "the perceived lack of feedback or contact with the teacher" is one of the barriers to distance learning. In response to this challenge and literature quoted, Duffy and Kirkley (2004:362) concluded after a survey done with students studying through the Suny Learning Network (an online education provider), that conversations with lecturers were critical for both learner satisfaction and learning ability. The challenge of autonomous learning can be substantiated from the literature on the transactional process of education. Garrison (2003:163) confirms that the "transaction process of education" - that is, the dialogue between learner and facilitator - is an important factor in learning. Peters $(2001: 28)$ indicates that the term "transactional distance" was later coined by Michael Moore in particular reference to distance education. He defined transactional distance as the communicative or mental and pedagogical or instructive distance between teachers and students. This distance is not necessarily undesirable, as it does promote independent learning; however, too great a distance prevents autonomous learning altogether (Peters, 2001:29). Further research frequently confirms this, in that distance learning conflicts with the process of constructing learning through dialogue with others, and that this impacts negatively on learning (Visser, Visser \& Simonson, 2005:74). When the concept of transactional dialogue is applied to the participants' experience, it emerges that communication with the lecturers is mainly unidirectional in the form of written material. This leaves learners in the position of not being able to question or interpret information should they not understand the written content. A descriptive study by Hara and King (1999) found that students who do not see each other or their instructors experience an absence of physical cues and this absence leads to some frustration among students; the main difficulty was expressed as being a lack of feedback on academic work. This feedback is important, as the concept of interaction, including feedback, is fundamental to the effectiveness of distance-education programmes as well as traditional ones (McIssac \& Gunawardena in Hara \& King, 1999). 
The compulsory attendance of workshops arranged by the Department was indicated as challenge for some of the participants. The participants in KZN, and especially the fourth-level students, made reference to this in stating:

These workshops, I don't think they are beneficial at all.

Well, we did discuss this with our facilitator at one stage and she said these workshops are compulsory and we should be here. We said: "We don't get what we want out of the workshops" and then when we raised the question, she said that she does what she is asked, she will do and that's it. So that's what angers us as students being fourth year, you want more out of the workshops.

Contrary to the sentiments shared by the participants above, the participants on second and third level in the KZN sample felt that they benefited from the workshops and in actual fact needed more workshops.

Another challenge experienced by the participants was in relation to their practical placements. They spoke about this along the following lines:

There is no social worker at my placement so everything I have to think I have to do on my own and there is no opportunity to learn if I am doing something wrong.

... my contact person at the department was never available ... she was not even supportive.

In commenting on this challenge, Lawlor (2008:45) writes that "Some fieldwork placements are not traditional social work settings, e.g. schools and clinics, with implications for the training of social work students ... In such settings the students report feeling unsupported". With reference to contact persons, Lawlor (2008:92) notes that many of the students "listed the lack of contact between Unisa and their contact person, rendering the contact person ineffective or confused about their role in the setting as one of the difficulties experienced in the field".

Category 3: Challenges relating specifically to the Unisa Learning Centre ${ }^{3}$ and Unisa's Stalwart Simulane Street Campus

The participants identified the following challenges in relation to the Durban Regional Office of the Department of Social Work situated in Boland House:

- "Library facilities are a problem because there are absolutely no facilities at Unisa's Learning Centre. There is absolutely nothing in Unisa's Learning Centre, no facilities, no photocopying, no library facilities, no finance departments, it is impossible to make any queries ... We find ourselves squashed in a small room... There is so much noise and you end up not concentrating".

- The Unisa Learning Centre does not provide parking for the students on weekdays: "There is no parking for students. We are expected to park outside and in outside parkades which are sometimes a problem because being in the centre of town, it is difficult to get parking. We find ourselves driving around looking for parking and [when] ... we get to our tutorials or workshops, in most cases we are late and in the case of our workshops we are actually marked down for coming in late”.

- Participants complained about the lifts at the Unisa's Learning Centre: "The lifts are a problem as well; I had an incident some time last year where I was stuck in the lift for

\footnotetext{
${ }^{3}$ Previously referred to as Durban Regional Office.
} 
almost three hours. There are only two lifts, sometimes it's a problem because fifty or sixty people are rushing to get to their tutorials on time. The lifts seem very very unsafe and... do not work properly most of the time..."

- The area around Unisa's Learning Centre is not safe: "Most of the taxis don't come to West Street [i.e. where the Learning Centre is] so some of them walk from the workshop ... which is quite hazardous, especially on a Saturday when we finish tutorials. After two o'clock it is basically very quiet, it is quite dangerous to walk down there to take the taxi".

- Travelling from the adjacent towns to Unisa's Learning Centre was time consuming and expensive, and the railway transport was "unreliable".

With reference to Unisa's Stalwart Simulane Street Campus the participants stated the following challenges:

- There was insufficient study space at the campus on Stalwart Simulane Street and the library was too small to accommodate a lot of students;

- There was a lack of computers;

- There was a need for transport for students from town to the campus: "I encountered a lot of Unisa students who walk from town to Stalwart Simulane. That distance actually requires transport".

Sub-theme: Time constraints as a challenge while studying to become a social worker

Another challenge (and biggest obstacle) indicated by participants is that of time constraints. This was due to the fact that studying social work requires a high volume of material to be read and assignments to be completed. In response to the question: "What challenges have you encountered in your studies", one participant replied: "Time. Time, time, time, time".

Most of the participants indicated that the course contained a lot of required work and the following excerpts are provided in confirmation of this:

It's just time consuming, you can't possibly get through all the stuff.

You know there's a lot of time that is needed for studies.

The pressure of completing the work was described as tiring and overwhelming. Participants expressed this in the following ways:

Studies are too much.

My day is a twenty hour day at this stage.

Kamya (2002:231) supports this finding by stating that many students find that the demands of social work training require long hours over the course of their studies (Collins, Coffey \& Morris, 2010:972).

Participants also expressed a negativity towards the workshops (referred to above as well) held at Unisa. For clarification, the workshops are mandatory one- to three-day training periods. They occur throughout the year and there are separate workshops for separate subjects. Participants felt that the workshops contributed extensively to their workload and used up a lot of needed time. One participant referred to this as follows:

So many demands ... next month - we are going to need to attend three days, three days away from work ... and it's mandatory attendance ... But it's just that it is too much, too much work and too challenging. 
The workshops were also identified as actually disrupting the study process as can be deduced from the following remark: "Time to go to the workshops that are also taking time, they are also disturbing the studies as well because you can't be at all practicals if you are on the workshops".

The challenge of specified meeting times, such as for the workshops referred to above, was also referred to by participants in Kazmer and Haythornthwaite's (2001:521) study. They found that the wedging of studies into non-reserved time became so important to students that they came to resent actual meeting times.

Because most of their time was absorbed by their studies, participants found that their leisure time had decreased. The following storylines are provided in support of this:

I have no time to go and visit.

I was never available to go out, never available to have fun.

Sub-theme: Balancing multiple roles as a challenge experienced while studying to become a social worker

While participants described the factors relating to studies as time consuming, they also highlighted other aspects of their lives as requiring time. This challenge identified by participants is that of balancing multiple roles. Peters $(2001: 12)$ states that those who enrol in distance learning differ from traditional students; this distinction lies in the fact that the students are mostly older adults. The participants indicated that they were responsible for a variety of roles, which distracted them from their studies. The responsibility of multiple roles was indicated by participants as follows:

I'm employed, I'm a mom, I'm a wife, I am also an employee who needs to be at work all the time so those are the challenges that I have faced. Yes there are many roles for me.

I have a lot of challenges at home as well as in terms of my family, two children, one is a teenager ... It is difficult to deal with them and their schoolwork. It becomes a problem as a mother and a wife to study.

It was indicated that these roles negatively affected studies and that studies negatively affected other roles. This was described by participants as follows:

I'm not going into the office that much. And I'm not able to spend as much time with family and friends as I'd like, because I've got so much to prepare for workshops and so much to prepare for the assignments ... So I don't go out with my friends, I don't meet them anywhere.

Yeah, the other roles are really suffering, other roles are really suffering. The primary focus for me at the moment is to study and pass at the end of the year.

Participants indicated trying to find a balance between the different roles. A particular difficulty was in relation to current employment. One participant highlighted this during the interview:

Well I think my challenge was to, with reference to the work and the studies, was to try and balance the two.

Balancing the role of work with studies also created a financial strain on participants by the negative impact studying had on their work performance. The participants said: 
I don't know how other students cope with work and studies - especially the fourth year ... I can say that I tried to balance the two but I know with my work it has been impacted by my studies.

I'm self-employed so it's having a big strain on my time to work ... it's putting a bit of financial strain.

As with the time constraints in the studies, participants again indicated that the workshops were the biggest obstacle in the area. This was described by one participant:

So every day that I'm at a workshop that starts at eight and ends at three, and an hour to get home to where I live, that's a full day's wages ... I'm battling financially because of it.

Adult learners who enrol in tertiary education later in life differ from traditional school leavers. Many students enrol in distance education because it provides them with an opportunity to complete their learning alongside job, family and community responsibilities (Duffy \& Kirkley, 2004:8). Regarding the sub-theme under discussion, the literature shows that adults face barriers to their education, which include lack of time to pursue education; family responsibilities; the scheduling of course time and place, and financial costs (Blakely \& Tomlin, 2008:282). Furthermore, adults fit education into schedules already dominated by work and family obligations (Blakely \& Tomlin, 2008:293). Adult students put themselves under a significant amount of pressure or stressors in adding university studies to their multiple activities and trying to balance competing roles (Boylston \& Blair, 2006:127). This can impact upon students' ability to complete graduation and stress can also precipitate physiological reactions in students (Boylston \& Blair, 2006:133). This could also be applied to the research participants as confirmed by the following utterance: "I'm sick; my body takes a lot of strain under the stress". Another participant stated as follows how the stress related to her studies estranged her from her family and friends: "I started out with a lot of support from my friends and family but then as the years went on family and friends got tired about hearing of all the stress I was under".

Boylston and Blair (2006:139) further found that a family crisis was the biggest determinant of stopping tertiary education. The students in their study claimed that balancing "family and school" was difficult. Mature learners seem to stop distance education for a number of reasons, with family and work responsibilities being the primary reasons. These learners are however more "stop-outs" than "drop-outs", often returning later when responsibilities permit (Visser $e t$ al., 2005:74; Chan in Kemp, 2001:35).

\section{SUMMARY AND CONCLUDING REMARKS}

This paper examined the motivations for studying to become a social worker, and studying at an ODL institution, as well as challenges faced while studying, by a sample of 21 participants from an ODL institution.

The participants (some of whom can be labelled as "adult learners") cited the fact of being parttime or full-time employees as one of the reasons for studying social work at an ODL institution. This reason, as well as the fact that Unisa was accessible and financially affordable, made this their institution of choice for pursuing their studies to become social workers.

Various motives (corresponding with findings in the literature) encouraged the participants to start and continue their studies to become social workers. The congruence or fit between the nature of social work and the self-structure of the participants; their passion for helping others; 
and becoming a social worker as the realisation of goal or dream were found to be the motives amongst the participants attracting them to enrol for studies in social work (Christie \& Kruk, 1998; Waterman, 2002). The enjoyment of what they were studying and current achievements experienced while studying social work provided the impetus and motivation necessary to continue and to complete (or work towards the completion of) their studies (Boylston \& Blair, 2006:131; Peers, 2003:171).

The challenges experienced by the participants while studying to become social workers concerned difficulties relating to distance education and difficulties experienced in relation to studying social work at an ODL institution. The challenges experienced in relation to distance education were subdivided into institutional, departmental and regional challenges.

With reference to institutional challenges the participants experienced difficulties in their contact with the Registration division at this institution. The inefficient service delivery by the Department of Finances and the section dispatching study material was also highlighted.

Departmental challenges (with reference to studying social work through Unisa, as an ODL institution) had to do with the lack of feedback from, and contact with, the lecturers. The geographical distance created a transactional distance which was challenging (Galusha n.d.; Garrison 2003:163; Hara \& King, 1999; Peters, 2001:28, 29; Visser et al., 2005:74). This forced some of the participants to construct their knowledge without an interaction process. This was described as difficult as many of the concepts were complex to understand and that it was hard to know what the lecturers expected of the students. Time constraints to attend the large number of workshops so frequently presented (especially at fourth-year level) and difficulties with practical placements (i.e. the absence of a social worker at the practical placement, lack of support from contact persons and high caseloads allocated to students) were also mentioned as challenges (Lawlor, 2008:45, 92).

Regional challenges noted, specifically concerning the Durban Regional office of the Department of Social Work and Unisa's Durban Campus, were a lack of transport between the campuses, lack of space to study, and the lack of computer, internet and library facilities at Unisa's Learning Centre Campus. Safe parking facilities at the aforementioned campus and that fact that this campus is in an unsafe area in Durban were also indicated as challenges experienced.

Time constraints were also mentioned as a challenge (which seemed to overwhelm some of the participants at times) because studying social work requires a high volume of material to read, assignments to complete and workshops to attend (Collins et al., 2010:972; Kamya, 2002:231; Kazmer \& Haythornthwaite, 2001:521). The time constraints experienced for the reasons provided above were intensified by the multiple role responsibilities the participants had to respond to, which corresponds with findings in the literature, especially when focusing on adult learners engaged in distance learning (Blakely \& Tomlin, 2008:282, 293; Boylston \& Blair, 2006:127, 132, 139).

\section{ACKNOWLEDGEMENT}

The researchers want to acknowledge the following fourth-year Unisa student social workers who participated in this research project by acting as fieldworkers and also analysed the data collected independently from the researchers: A Bromley, $\mathrm{H}$ Bhola, I Budhu, F Motala and K Naidoo. 


\section{BIBLIOGRAPHY}

ALDERMAN, K.M. 2004. Motivation for achievement: possibilities for teaching and learning $\left(2^{\text {nd }}\right.$ ed). New Jersey: Lawrence Erlbaum Associates.

BLAKELY, P. \& TOMLIN, A. 2008. Adult education: issues and developments. New York: Nova Science Publishers.

BOYLSTON, M. \& BLAIR, A. 2006. Minimizing the stress of accelerated adult education: a descriptive study. In: LANDOW, M.V. (ed) Stress and mental health of college students. New York: Nova Science Publishers.

CHRISTIE, A. \& KRUK, E. 1998. Choosing to become a social worker: motives, incentives, concerns and disincentives. Social Work Education, 17(1):21-33.

COLLINS, S., COFFEY, M. \& MORRIS, L. 2010. Social work students: stress, support and well-being. British Journal of Social Work, 40:963-982.

COLLINS, S. 2008. Open and distance learning in qualifying social work education in Britain and the USA: celebrating diversity and difference? Social Work Education, 27(4):422-439.

CRESWELL, J.W. 1994. Research design: qualitative and quantitative approaches. Thousand Oaks, California: Sage Publications.

CRESWELL, J.W. 2003. Research design: qualitative, quantitative and mixed method approaches $\left(2^{\text {nd }}\right.$ ed). Thousand Oaks, California: Sage Publications.

DONALEK, J.G. \& SOLDWISCH, S. 2004. Demystifying nursing research: an introduction to qualitative research methods. Urologic Nursing, 24(4):354-356.

DUFFY, T.M. \& KIRKLEY, J.R. 2004. Learner-centred theory and practice in distance education: cases from higher education. New Jersey: Lawrence Erlbaum Associates.

FOSSEY, E., HARVEY, C., McDERMOTT, F. \& DAVIDSON, L. 2002. Understanding and evaluating qualitative research. Australian and New Zealand Journal of Psychiatry, 36:717-732.

GALUSHA, J.M. nd. Barriers to learning in distance education. [Online] Available: http://infrastruction.com/barriers.htm [Accessed: 13/09/2010].

GARRISON, R. 2003. Self-directed learning and distance education. In: MOORE, M. \& ANDERSON, W. (eds) Handbook of distance education. New Jersey: Lawrence Erlbaum Associates.

HARA, N. \& KING, R. 1999. Student's frustrations with web-based distance education course. First Monday, 4(12). [Online] Available: http://firstmonday.org/htbin/cgiwrap/bin/ojs/index. php/fm/article/viewArticle/710/620 [Accessed: 05/07/2009].

HOLLOWAY, I. \& WHEELER, S. 1998. Qualitative research for nurses. Great Britain: MPG Books.

IFE, J. 2001. Human rights and social work: towards rights-based practice. New York: Cambridge University Press.

JANSEN, J.D. 2007. The research question. In: MAREE, K. (ed) First steps in research. Pretoria: Van Schaik Publishers.

KAMYA, H.A. 2002. Hardiness and spiritual well-being among social work students: implications for social work education. Journal of Social Work Education, 36(2):231-241. 
KAZMER, M.M. \& HAYTHORNTHWAITE, C. 2001. Juggling multiple social worlds: distance students online and offline. The American Behavioral Scientist, 45(3):510-529.

KEEGAN, D. 1996. Foundations of distance education. New York: Routledge.

KEMP, W. 2001. Persistence of adult learners in distance education. Alberta: Athabasca University. (MA Thesis).

KREFTING, L. 1991. Rigor in qualitative research: the assessment of trustworthiness. The American Journal of Occupational Therapy, 45(3):214-222.

KVALE, S. 1996. Interviews: an introduction to qualitative research interviewing. Thousand Oaks, Calif: Sage Publications.

LANGFORD, R.W. 2001. Navigating the maze of nursing research: an interactive learning adventure. London: Mosby.

LAWLOR, G.M. 2008. Finding fit between personal context, learning context and work context of students to further practice excellence in social work. Pretoria: University of South Africa. (Unpublished MA Dissertation)

LINTVELT, R.A. 2008. The personal contexts of undergraduate students in social work at Unisa. Pretoria: University of South Africa. (Unpublished MA Dissertation)

MAREE, K. \& PIETERSEN, J. 2007. Sampling. In: MAREE, K. (ed) First steps in research. Pretoria: Van Schaik Publishers.

MOSIMEGE, K.B. 2006. Multiplicity of roles: experiences of mature women students in a higher education setting. University of Pretoria: Pretoria. (Unpublished MA Dissertation)

NEUMAN, L.W. 2000. Social research methods: qualitative and quantitative approaches $\left(4^{\text {th }}\right.$ ed). London: Allyn \& Bacon.

PEERS, R. 2003. Adult education: a comparative study. London: Routledge.

PETERS, O. 2001. Learning and teaching in distance education: pedagogical analyses and interpretations in an international perspective (rev ed). Open University: Institute of Educational Technology. London: Routledge.

RABIDEAU, S. 2005. Effects of achievement motivation on behaviour. Rochester Institute of Technology. [Online] Available: http://www.personalityresearch.org/papers/rabideau.html [Accessed: 08/07/2009].

ROGERS, P. \& HOWARD, C. 2009. Encyclopaedia of distance learning ( $2^{\text {nd }}$ ed). USA: Idea Group Inc (IGI).

ROMANDO, R. 2007. Achievement motivation [Online] Available: http://ezinearticles.com/ Achievement-Motivation\&id=429438 [Accessed: 08/07/2009].

ROYSE, D. 2008. Research methods in social work $\left(5^{\text {th }} \mathrm{ed}\right)$. Belmont: Thomson Brooks/ Cole.

SCHENCK, R. 2009. The socio-economic realities of the social work students of the University of South Africa. Social Work/Maatskaplike Werk, 45(3):299-313.

UNGAR, M. 2003. Qualitative contributions to resilience research. Qualitative Social Work, 2(1):85-102.

UNISA. 2006. 2015 Strategic Plan: an agenda for transformation. Pretoria: University of South Africa. 
450

UNISA. 2008. Self-evaluation portfolio for the HEQC institutional audit. Pretoria: University of South Africa.

VISSER, Y., VISSER, L. \& SIMONSON, M. 2005. Trends and issues in distance education: international perspectives. USA: Information Age Publishing.

WADE, B. 2010. Unisa social work students' experiences of trauma: an exploratory study from a person-centred perspective. Pretoria: University of South Africa. (Unpublished Thesis).

WATERMAN, B.T. 2002. Motivations for choosing social service as a career [Online] Available: www.bedrugfree.net. [Accessed: 13/09/2010].

Prof AH (Nicky) Alpaslan; Dr Jouberto Lombard, Department of Social Work, UNISA, Pretoria, South Africa. 